\title{
A novel approach to investigating indoor/outdoor pollution links: \\ combined magnetic and PAH measurements
}


C. J. Halsall; B. A. Maher; V. V. Karloukovski; P. Shah; S. J. Watkins. Lancaster Environment Centre, Lancaster University, Lancaster LA 1 4YQ, UK 


\title{
A novel approach to investigating indoor/outdoor pollution links: combined magnetic and PAH measurements
}

\author{
C. J. Halsall*; B. A. Maher; V. V. Karloukovski; P. Shah; S. J. Watkins. \\ Lancaster Environment Centre, Lancaster University, Lancaster LA1 4YQ, UK \\ *author for correspondance \\ c.halsall@lancaster.ac.uk
}

Tel : (0)1524 594330

Fax : (0)1524 593985

\begin{abstract}
In a preliminary study, paired indoor and outdoor air sampling was conducted at three locations around the city of Lancaster, UK to examine the influence of combustion sources on air quality by measuring particulate concentrations, particulate magnetic properties and polyaromatic hydrocarbons (PAHs). With one exception (an indoor suburban air sample), outdoor air samples had higher total suspended particulates (TSP), particle-bound PAH concentrations and magnetic remanence (IRM) values. IRM values were highest for the week-day, outdoor city centre samples and then declined in the sequence: Sunday, city centre $>$ suburban/residential > Lancaster University campus. These data indicate traffic as the major particle-bound $\mathrm{PAH}$, particulates and magnetic source, particularly as sampling was conducted during July in the absence of any space heating. The indoor air samples revealed a wide variation in pollutant concentrations, characterised by higher vapour levels of 2-3 ring PAHs, variable TSP concentrations and variable but generally low IRMs. The differences in PAH concentrations, TSP and IRMs between outdoor and indoor environments indicate limited ingress of outdoor air pollutants to the indoor environment in this study. Our combined PAH and magnetic data identify specific and distinctive indoor pollution signals for each of our sampled sites, reflecting distinct sources. One site, the suburban house, has anomalously high IRM, TSP and particle-bound PAHs. A possible source for these is a cast iron, wood-burning stove (even though not lit). The city centre indoor site is characterised by high TSP and very low IRMs but high values of the magnetic ratio of anhysteretic remanence:saturation remanence, indicative of ultrafine (submicrometre) magnetic grain sizes. The source for this city centre indoor signature is unidentified but may reflect the occupant smoking and/or lighting candles. The indoor campus sample was affected by loss-
\end{abstract}


on-ignition procedures carried out in a teaching laboratory. The combined PAH and magnetic analyses thus provide a sensitive and discriminatory means of identifying outdoor, trafficderived pollution, and of discriminating between different types of indoor pollution.

Key words: pollution, particulate, PAHs, magnetic discrimination.

\section{Introduction}

Increasing attention has been focused recently on health effects of exposure to air pollution, especially regarding increased risk of morbidity and mortality from cardio-vascular disease, cancer, degenerative brain disease, and respiratory illness (e.g. Knutsen et al., 2004; Pope et al., 2002; Schwartz et al., 1996; Schwarze et al., 2006; Calderón-Garcidueñas et al., 2004). For many pollutants, air quality standards refer to levels measured in ambient outdoor air. The sources of fine, combustion-derived pollutants are less well understood for the indoor environment, prompting studies of relationships between outdoor sources and indoor air quality (e.g. Fischer et al., 2000; Kingham et al., 2000; Naumova et al., 2002). Urban sources of particles and organic pollutants (volatile and semi-volatile) vary, but principally arise from fuel combustion by vehicles, and for space heating and waste incineration. Within the U.K., health-based air quality standards exist for several key air pollutants, including $\mathrm{PM}_{10}$ (particles with diameter $<10 \mu \mathrm{m})$ and benzo $[a]$ pyrene $(\mathrm{B}[a] \mathrm{P})$, a high molecular weight (MW) PAH, formed during combustion. Both $\mathrm{PM}_{10}$ (plus finer modes) and PAHs are frequently measured in pollution studies (e.g. Fischer et al., 2000; Kingham et al., 2000; Kaur et al., 2005). Recently, aerosol magnetic measurements have been used successfully to assess urban, traffic-related pollution, both in conjunction with conventional fixed monitoring station air sampling (Sagnotti et al., 2006; Muxworthy et al., 2002) and using roadside tree leaves as natural biomonitoring surfaces (e.g. Matzka \& Maher, 1999; Maher et al., 2008; Gautam et al., 2005). Magnetic particles are invariably present amongst atmospheric aerosol, from release of iron-containing impurities in fossil fuels and/or through metal wear (abrasion/corrosion). These iron-rich emission particles are magnetic, the most common

phases being magnetite $\left(\mathrm{Fe}_{3} \mathrm{O}_{4}\right)$ and haematite $\left(\alpha \mathrm{Fe}_{2} \mathrm{O}_{3}\right)$, with magnetisations easily measurable using a cryogenic magnetometer (e.g. Flanders, 1994). In urban dusts, strong correlation has been observed between magnetic susceptibility and/or magnetic remanence values and $\mathrm{PM}_{10}$ dust-mass (e.g. Sagnotti et al., 2006), sample mutagenicity (Morris et al., 1995) and lead and iron concentrations (Gautam et al., 2005; Maher et al., 2008). In areas 
dominated by vehicle pollution, rather than industrial point sources (Hanesch et al., 2003), magnetic measurements appear to provide a robust, rapid and cheap proxy for vehiclederived particulate pollution (Matzka and Maher, 1999), enabling high-resolution spatial and temporal sampling.

Here, we present a pilot study to examine the links between outdoor and indoor air pollution, innovatively combining magnetic and $\mathrm{PAH}$ measurements at different locations in Lancaster, England. By simultaneously measuring indoor and outdoor concentrations of TSP, magnetic properties and PAHs, assessment can be made of their sources and whether incursions of outdoor, traffic-derived pollution influence the indoor environment at these sites.

\section{Methods}

\subsection{Air sampling}

Air samples were collected (summer 2003) using high volume (Hi-Vol) air samplers at three separate sites, comprising: Lancaster University campus (LUC); a detached suburban house SUB); and a city centre location (CC) Two Graseby-Anderson PS-1 Hi-Vol air samplers were co-deployed at each site, to sample both indoor and outdoor air. As far as possible, the samplers were sited away from vents, obstructions or local point sources (e.g. cooker, fireplace). The indoor locations comprised a teaching laboratory (LUC), a domestic kitchen (SUB) and an upstairs, two-storey apartment (CC). At the outdoor locations, a Hi-Vol was located in a grassed courtyard (LUC), a residential garden (SUB) and close ( $\sim 2 \mathrm{~m}$ ) to a major road $(\mathrm{CC})$. The outdoor samplers were placed $\sim 10 \mathrm{~m}$ away from any building/obstruction, with the sample head at $\sim 1.5 \mathrm{~m}$ above ground level. Air samples were taken during June July 2003, a warm, continuously dry interval, without indoor space heating. At each site, 2-3 samples of outdoor and indoor air were collected, with air sample volumes ranging between $63.5-350 \mathrm{~m}^{3}$, over a 6 to 24 hour period (Table 1). For the magnetic measurements, one HiVol sampler was fitted with a magnetically-clean Millipore Fluoropore ${ }^{\mathrm{TM}}$ membrane (PTFE) filter $(1 \mu \mathrm{m}$ pore-size) for particle collection; the other with a Whatman glass-fibre filter (GFF) and two polyurethane foam (PUF) plugs, for sampling particle-bound and vapour PAHs, respectively. 


\subsection{Analysis of TSP, PAHs and magnetic properties.}

Following sampling, each Hi-Vol sample head (sealed in zip-lock plastic bags) was returned to the laboratory where the GFF/PUFs were stored in a freezer $\left(-20^{\circ} \mathrm{C}\right)$ prior to analysis. TSP values were determined gravimetrically using the PTFE filters (pre-weighed), placed in a modified vacuum desiccator maintained at nominal but constant humidity.

For PAH analysis, both GFFs and PUF plugs underwent separate soxhlet extraction in dichloromethane $(\mathrm{DCM})$ for $16 \mathrm{~h}$. Extracts were then concentrated on a Buchi-rotary evaporator $(\sim 1 \mathrm{~mL})$ and subjected to column chromatography to remove co-extractants. Each sample was eluted through alumina( $1 \mathrm{~g}) /$ silica(1g) with $25 \mathrm{~mL}$ of $1: 1 \mathrm{DCM} / n$-hexane. The eluant was gently reduced in volume under a stream of pure $\mathrm{N}_{2}$ allowing solvent exchange to acetonitrile $\left(\mathrm{CH}_{3} \mathrm{CN}\right)$, with a final sample volume of $500 \mu \mathrm{L}$. Analysis was performed on a Perkin-Elmer HPLC, with an auto-sampler (20 $\mu \mathrm{L}$ injection volume) and an LS-40 Fluorescence Detector. PAHs were separated on a ChromSep $\mathrm{C}_{18}$ reverse-phase column using a mobile phase comprising $\mathrm{CH}_{3} \mathrm{CN} / \mathrm{H}_{2} \mathrm{O}$. The detector was programmed with excitation/emission wavelengths ranging between 200-420 nm. Qualification of 15 separate PAHs (Table 1) was based on comparative retention times with a PAH standard (containing all the PAHs), and quantification achieved using six calibration standards ranging from $10-$ $400 \mathrm{ng} / \mathrm{mL}$, run at the start and end of each sample batch. Four samples (2 GFF and 2 PUF LUC, SUB) were also analysed by GC-MS (HP5890 Series-II GC and HP5972 MSD), with sample extracts taken up in $n$-hexane $(500 \mu \mathrm{L})$ rather than $\mathrm{CH}_{3} \mathrm{CN}$, followed by the addition of three deuterated-PAH internal standards (fluorene- $\delta 10$, pyrene- $\delta 10$ and $\mathrm{B}[\mathrm{a}] \mathrm{P}-\delta 10$ ). The GC-MS protocol for PAH analysis (Smith, 2000) involved a cool $\left(60^{\circ} \mathrm{C}\right)$ on-column injection $(1 \mu \mathrm{L})$ with subsequent PAH separation on a 30m HP5MS column (with a $2 \mathrm{~m}$ deactivated retention gap) connected to the MSD (EI source $(70 \mathrm{eV})$ operating in SIM). Quantification was based on two sets of calibration standards to cover the linear ranges of $1-100 \mathrm{ng} / \mathrm{mL}$ and $100-2500 \mathrm{ng} / \mathrm{mL}$.

For magnetic analysis, each PTFE filter was subjected to acquisition of anhysteretic remanence (ARM), imparted using a Molspin AF demagnetiser with a peak A.F. of 85 milliTesla (mT) and D.C. field of $0.08 \mathrm{mT}$, measured using a cryogenic magnetometer (CCL Ltd., with a noise level of $10^{-10} \mathrm{Amperes}(\mathrm{A}) \mathrm{m}^{2}$ ). ARM is expressed here as a susceptibility of ARM $\left(\chi_{\text {ARM }}\right)$, normalised by the D.C. field. After A.F. demagnetisation of the ARM, each sample was magnetised (at room temperature) using incremental, pulsed D.C. fields of 100 and $300 \mathrm{mT}$, using a Molspin Pulse Magnetiser, and then 1 Tesla (T), using a Newport 
electromagnet. The magnetic remanence (IRM) was measured immediately after each magnetising step. IRM values were normalised for air sample volume $\left(\mathrm{Am}^{2} / \mathrm{m}^{3}-\right.$ thus $\left.\mathrm{Am}^{-1}\right)$ and particulate mass $/ \mathrm{m}^{3}$ of sampled air $\left(\mathrm{Am}^{-1} \mathrm{~g}^{-1}\right)$.

\subsection{Quality controls}

GFFs were baked overnight at $450{ }^{\circ} \mathrm{C}$ prior to use and PUF plugs were pre-cleaned via soxhlet extraction in DCM for $24 \mathrm{~h}$. A set of GFF \& PUF field blanks was generated for each location with contamination found to be low. GC-MS analysis of blanks and samples revealed the presence of several methylated naphthalenes and phenathrenes, but these are not reported here due to their erratic occurrence in the blank PUFs, and subsequent high method detection limits. Comparison between the LC and GC results was good, individual PAH concentrations varying by $\pm 15 \%$. Precision and accuracy of the HPLC and GC-MS methods have been detailed in Halsall et al. (1994) and Smith (2000) and Herbert et al. (2004), respectively. Dibenz $[a, h]$ anthracene was used as a recovery standard, spiked onto both the GFF and PUFs prior to soxhlet extraction; recoveries always exceeded $80 \%$, samples were not recovery corrected.

Sample magnetic values were corrected for the (very low) blank PTFE filter values $\left(\mathrm{ARM}<1 \times 10^{-10} \mathrm{Am}^{2} ; \mathrm{SIRM}<20 \times 10^{-10} \mathrm{Am}^{2}\right)$. GFFs were unsuitable for magnetic analyses, due to high blank magnetic remanences. All magnetic measurements were carried out without knowledge of sample site or date.

\subsection{Statistical analysis.}

A multivariate statistical method, non-linear mapping (NLM, using the programme of Vriend et al., 1988), was applied to the combined magnetic and PAH datasets. NLM scales and calculates the distance between datapoints in multidimensional space, then translates this into two dimensions (Vriend et al., 1988). Three diagnostic magnetic parameters were included: SIRM (mass-normalised), $\chi_{\text {ARM }} / S I R M$, and the percentages of high-field IRM (HIRM, i.e. the remanence acquired between 300 and $1000 \mathrm{mT}$ ). The SIRM reflects the concentration of magnetic minerals, the $\chi_{\mathrm{ARM}} / \mathrm{SIRM}$ ratio the contribution of ultrafine magnetite grains $(\sim 20$ $30 \mathrm{~nm}$ ), and HIRM the presence of haematite (if the HIRM resists subsequent demagnetisation). Data for two PAHs were also included: total phenanthrene (3 ring PAH) and $\mathrm{B}[a] \mathrm{P}$ (5 ring $\mathrm{PAH})$. Before analysis, the parameters were tested for autocorrelation using the non-parametric Spearman test. 


\section{Results.}

\subsection{PAHs, suspended particulate concentrations.}

Table 1 summarises the PAH concentrations observed at the three sites. For the outdoor air, highest PAH concentrations were observed at the city centre, with values within the ranges measured in other, UK urban environments. For example, from the UK's Toxic Organic Micropollutants Survey, $\mathrm{PPAH}$ concentrations ranged from $\sim 20-150 \mathrm{ng} / \mathrm{m}^{3}$ in London and Manchester, respectively (Coleman et al., 1997). Similarly, roadside measurements in Birmingham revealed $\Sigma$ PAH concentrations between 28.5-54.8 ng/m ${ }^{3}$ (Dimashki et al., 2001). However, here the $\Sigma$ PAH concentrations (Table 1) are dominated by the lower MW, 2-3 ring compounds of acenaphthene, fluorene and phenanthrene, with the highest concentrations of these predominantly vapour phase compounds observed in indoor air, particularly at the campus and suburban sites. Average individual PAH concentrations for both indoor and outdoor air (Figure 1) illustrate the dominance of the lower MW compounds in indoor air and the higher MW PAHs in outdoor air. The high PAH concentrations in indoor air at the campus and suburban sites will be discussed later, but the campus was the only indoor site where concentrations of the higher MW, particle-bound PAHs were comparable with the city centre outdoor air. TSP concentrations (Figure 2) ranged from 20$125 \mu \mathrm{g} / \mathrm{m}^{3}$, the highest concentration observed in one indoor sample from the suburban house. High levels of TSP $\left(60-95 \mu \mathrm{g} / \mathrm{m}^{3}\right)$ were also observed in the indoor air of the city centre apartment. For the outdoor air samples, highest TSP concentrations were measured at the city centre (mean $40 \mu \mathrm{g} / \mathrm{m}^{3}$ ).

\subsection{Magnetic properties}

Figure 3 shows the SIRMs for each indoor and outdoor site, normalised with air volume (a) and particulate mass (b), respectively. On an air-volume basis, sites with notably high SIRM values are the suburban indoor and two of the city centre outdoor samples. When normalised for particulate mass, the two city centre outdoor samples (sampled on week days), and the suburban indoor samples display enhanced SIRMs, compared with very low values for the other indoor samples. The remaining outdoor city centre sample (sampled on a Sunday) has an SIRM comparable with the outdoor suburban and campus samples. The percentage of IRM acquired below $100 \mathrm{mT}$ varies from $62-76 \%$; all the outdoor samples (mean $72 \%$ ) show higher values than indoors (mean $67 \%$ ). After application of a $300 \mathrm{mT}$ field, the samples had acquired $94-98 \%$ of their SIRM. The suburban indoor samples are notable 
(figure 4); they display greatest high-field acquisition (i.e. 5-6\% IRM gain between 300 $\mathrm{mT}$ and $1 \mathrm{~T}$ ) but most of this high-field remanence is unstable and lost upon A.F. demagnetisation at $100 \mathrm{mT}$, behaviour characteristic of maghemite, the oxidised counterpart of magnetite (Liu et al., 2002; Maher et al., 2004). All the other samples retain varying proportions of their HIRM, indicating the presence of 'hard' haematite-like phases. Highest $\chi_{\mathrm{ARM} / \mathrm{SIRM}}$ ratios (figure 4$)$, reflecting the presence of submicrometre $(\sim 20-30 \mathrm{~nm})$ ferrimagnets (Maher, 1988; Özdemir \& Banerjee, 1982), characterise the city centre indoor samples; all the outdoor samples display moderate values, indicative of ferrimagnets of $\sim 1$ $\mu \mathrm{m}$ (Ozdemir \& Banerjee, 1982; Maher, 1988).

Figure $5 \mathrm{a}$ and $\mathrm{b}$ summarise the relationships between the SIRM values (massnormalised) and phenanthrene and $\mathrm{B}[a] \mathrm{P}$ concentrations (where detectable). The two weekday city centre outdoor samples display high SIRM and $\mathrm{B}[a] \mathrm{P}$ values (figure $5 \mathrm{a}$ ), in contrast with the Sunday sample, with relatively low SIRMs and moderate $\mathrm{B}[a] \mathrm{P}$ values, similar to the two suburban outdoor samples. The campus outdoor samples display moderate SIRM and low $\mathrm{B}[a] \mathrm{P}$. Sample clustering is also evident in figure $5 \mathrm{~b}$. The two week-day city centre outdoor samples, and one suburban indoor sample, show high SIRM and very low phenanthrene values. The Sunday city centre outdoor sample groups with the other outdoor samples, with low/moderate SIRMs and very low phenanthrene values. The city centre indoor samples are distinctive, with minimal SIRM and maximal phenanthrene values.

With the caveat of the small sample size, the magnetic property and PAH data can be combined, to optimise sample characterisation and differentiation, by applying non-linear mapping. Not only is separation of outdoor from the indoor samples evident (figure 6); the indoor samples also show distinct and separate groupings. The city centre outdoor samples cluster, with high SIRM and high $\mathrm{B}[a] \mathrm{P}$ values, as do the suburban and campus outdoor samples, these characterised by low phenanthrene and moderate SIRM values. The suburban indoor samples and one of the campus indoor samples (coinciding with laboratory loss-onignition experiments) approach the outdoor sample grouping. The city centre indoor samples form a separate, clustered group.

\section{Discussion.}

The relatively high concentrations of 2-3 ring PAHs in the indoor environments sampled here mirror results from an extensive U.S. survey, part of the Relationship of Indoor, Outdoor and Personal Air (RIOPA) study (e.g. Naumova et al, 2002). In RIOPA, इPAH concentrations in 
indoor air exhibited a wide range in concentrations $\left(\sim 16-350 \mathrm{ng} / \mathrm{m}^{3}\right)$ with the upper range exceeding that found in the corresponding outdoor atmospheres. High levels of 3-4 ring PAHs in indoor air accounted for these high concentrations while conversely, the heavier 5-7 ring PAHs were found to have higher concentrations in the outdoor air. The results from our study are in broad agreement, but distinctive indoor combustion sources may have produced PAH anomalies at our campus and suburban indoor sites. The notably high indoor PAH concentrations at the campus (both vapour- and particle-bound PAH), associated with low TSP and IRMs, were probably due to soil combustion in a laboratory furnace (a procedure carried out at the time of sampling). At the suburban site, indoor air concentrations of the lighter PAHs were high, and associated with high TSP concentrations and SIRMs. We suggest this distinctive signature reflects the presence of a cast-iron, solid-fuel stove in the room adjacent to the air sampler. While this stove was not in use during sampling, the presence of wood ash in an open iron grate may account for both the high particulate loading and magnetisations (i.e. large numbers of Fe-containing and ferrimagnetic particles), accompanied by high particle-bound concentrations of 2-3 ring PAHs. Similarly, the indoor air at the city centre apartment also contained elevated 2-3 ring PAH concentrations relative to the outdoor air samples. Whilst its TSP concentrations were similar to the outdoor air, it displays much lower SIRM values (both volume- and mass-normalised), and high $\chi_{\mathrm{ARM} /} \mathrm{SIRM}$ ratios (figure 4), indicating the presence of sub-micrometre magnetic grains, again suggesting a specific and distinctive indoor source. (Sub-micrometre magnetic particles often occur as interacting agglomerates, and hence are effectively sampled even on the $1 \mu \mathrm{m}$ pore-size filter used).

In summary, the indoor air samples show wide variation over the three study sites, with PAHs, magnetic properties and TSP concentrations reflecting distinctive indoor sources. While the small number of samples precludes statistical comparison between outdoor and indoor concentrations of particles, PAHs and magnetic particles, there is little evidence of ingress of outdoor air as a source of these pollutants. Particulate PAH concentrations and SIRM both differ markedly between indoor and outdoor environments. Hence, several of the indoor air samples appear as outliers (e.g. LUC- I1, 2 and CC-I1, 3 in Figure 4), grouped separately from the outdoor samples. For the outdoor samples, while their range of $\chi_{\text {ARM }}$ SIRM values is quite narrow $\left(\sim 10-15 \times 10^{-5} \mathrm{~A} / \mathrm{m}\right)$, statistically significant correlations are observed between $\chi_{\mathrm{ARM} / \mathrm{SIRM}}$ ratios and particulate-concentrations of phenathrene and $\mathrm{B}[a] \mathrm{P}$ $\left(\mathrm{r}^{2}=0.55, \mathrm{n}=7, p<0.05\right.$ and $\mathrm{r}^{2}=0.68, \mathrm{n}=7, p<0.05$, respectively $)$, with $\chi_{\mathrm{ARM} / S I R M}$ ratios 
declining in the order city centre>suburban>campus. This trend indicates finer magnetic particle sizes at the city centre and a significant link between ultrafine magnetic particles and PAHs. This link is likely to be controlled by traffic emissions, given that outdoor samples from the city centre had the highest particulate PAH concentrations and high SIRM $(>425$ $\mathrm{x} 10^{-4} \mathrm{Am}^{-1} \mathrm{~g}^{-1}$ ). Association of PAHs with finer particle fractions (e.g. $<1 \mu \mathrm{m}$ diameter) has been demonstrated in the urban environment and in vehicle emissions (e.g. Allen et al 1996; Zielinska et al., 2004). Notably, the outdoor city centre sample collected on a Sunday (CCO1), when traffic was reduced, had lower PAH concentrations and SIRM values than the week-day samples (CC-O2 and 3); the Sunday city centre values are similar to the week-day suburban outdoor samples.

As shown by NLM, the combined magnetic and PAH analyses enable discrimination not only between outdoor and indoor pollution signals but also between different types of indoor source.

\section{Conclusions}

- This pilot study reveals notable differences between the pollution characteristics particles, PAHs and magnetic properties - of indoor air from three different sampling sites. It suggests that indoor pollution sources vary significantly and there is little evidence of the incursion of outdoor air, even in a city centre environment.

- The combined particle-bound PAH and magnetic data provide a powerful tool to classify samples according to likely sources and may provide a valuable diagnostic tool to discriminate between indoor and outdoor combustion sources. Magnetic measurements may provide a sufficiently specific marker for traffic-derived pollution for use in studies of health effects of vehicle pollution exposure.

- Given increasing evidence for damage to human health attributable to exposure to traffic-derived pollution, especially for children, more detailed investigation and implementation of these methods seems warranted and timely, preferably using passive collectors co-deployed in a variety of indoor environments (different rooms) and outdoor locations (especially with regard to traffic proximity).

\section{Acknowledgements.}


The support of the Royal Society through a Royal Society-Wolfson Research Award to BAM and a Lancaster University research award are both gratefully acknowledged. CJH would like to thank Vicky Burnett for help with the PAH analysis.

\section{References}

Allen, J. O.; Dookerna, N. M.; Smith, K A.; Sarofilm, A. F.; Taghizadeh, K.; Lafleur, A. L., 1996. Measurement of polycyclic aromatic hydrocarbons associated with sizesegregated atmospheric aerosols in Massachusetts. Environmental Science \& Technology 30, 1023-1031.

Calderón-Garcidueñas, L., Reed, W., Maronpot R.R., Henríquez-Roldán C., Delgado-Chavez R., Calderón-Garcidueñas A., Dragustinovis, I., Franco-Lira, M., Aragón-Flores, M., Solt, A.C., Altenburg, M., Torres-Jardón, R., Swenberg, J.A., 2004. Brain inflammation and Alzheimer's-like pathology in individuals exposed to severe air pollution. Toxicology Pathology 32(6), 650-8.

Coleman P. J., Lee, R. G. M., Alcock, R. E., Jones, K. C. 1997. Observations on PAH, PCB, and PCDD/F trends in UK urban air 1991-1995. Environmental Science \& Technology $31,2120-2124$.

Dimashki, M.; Lim, L. H.; Harrison, R. M.; Harrad, S., 2001. Temporal trends, temperature dependence and relative reactivity of atmospheric polycyclic aromatic hydrocarbons. Environmental Science \& Technology, 35, 2264-2267.

Fischer, P.H., Hoek, G., van Reeuwijk, H., Briggs, D.J., Lebret, E., van Wijnen, J.H., Kingham, S., Elliott, P.E., 2000. Traffic-related differences in outdoor and indoor concentrations of particles and volatile organic compounds in Amsterdam. Atmospheric Environment 34, 3713-3722.

Flanders, P.J., 1994. Collection, measurement, and analysis of airborne magnetic particulates from pollution in the environment, Journal Applied Physics 75, 5931-5936.

Gautam, P., Blaha, U. Appel, E., 2005. Magnetic susceptibility of dust-loaded leaves as a proxy for traffic-related heavy metal pollution in Kathmandu city, Nepal. Atmospheric Environment 39, 2201-2211.

Halsall, C. J.; Coleman, P. J.; Davis, B. J.; Burnett, V.; K. S. Waterhouse, Harding-Jones, P.; Jones, K. C. 1994. Polycyclic aromatic hydrocarbons in UK urban air. Environmental Science \& Technology 28, 2380-2386. 
Hanesch M, Scholger R, Rey D., 2003. Mapping dust distribution around an industrial site by measuring magnetic parameters of tree leaves. Atmospheric Environment 37, 51255133.

Herbert, B. M. J., Halsall, C. J.,Fitzpatrick, L., Villa, S., Jones, K. C., Thomas, G. O., 2004. Use and validation of novel snow samplers for hydrophobic, semi-volatile organic compounds (SVOCs). Chemosphere 56, 227-235.

Kaur, S., Nieuwenhuijsen, M, Colvile, R., 2005. Personal exposure of street canyon intersection users to $\mathrm{PM}_{2.5}$, ultrafine particle counts and carbon monoxide in central London, UK. Atmospheric Environment 39, 3629-3641.

Kingham, S., Briggs, D., Elliott, P., Fischer, P., Lebret, E., 2000. Spatial variations in the concentrations of traffic-related pollutants in indoor and outdoor air in Huddersfield, England. Atmospheric Environment 34, 905-916.

Knutsen, S., Shavlik, D., Chen, L.H., Beeson, W.L., Ghamsary, M., Petersen, F., 2004. The association between ambient particulate air pollution levels and risk of cardiopulmonary and all-cause mortality during 22 years follow-up of a non-smoking cohort. Results from the AHSMOG study. Epidemiology, 15 S45-S45.

Liu, Q., Banerjee, S.K., Jackson, M.J., Zhu, R., Pan, Y., 2002. A new method in mineral magnetism for the separation of weak antiferromagnetic signal from a strong ferrimagnetic background, Geophysical Research Letters, 29 6-1-4.

Maher, B.A., 1988. Magnetic properties of some synthetic sub-micron magnetites. Geophysical Journal Royal Astronomical Society, 94, 83-96.

Maher, B.A., Moore, C. \& Matzka, J. (2008) Spatial variation in vehicle-derived metal pollution identified by magnetic and elemental analysis of roadside tree leaves.

Atmospheric Environment, 42, 364-373 (doi.org/10.1016/j.atmosenv.2007.09.013).

Maher, B.A., Karloukovski, V.V. \& Mutch, T.J., 2004. High-field remanence properties of synthetic and natural submicrometre haematites and goethites: significance for environmental contexts. Earth and Planetary Science Letters, 226, 491-505.

Matzka, J., Maher, B. A. 1999. Magnetic biomonitoring of roadside tree leaves: identification of spatial and temporal variations in vehicle-derived particulates. Atmospheric Environment 33, 4565-4569.

Morris, W. A., Versteeg, J. K., Bryant, D. W., Legzdins, A. E., McCarry, B. E., Marvin, C. H., 1995. Preliminary comparison between mutagenicity and magnetic susceptibility of respirable airborne particulates. Atmospheric Environment 29, 3441-3450. 
Muxworthy, A.R., Schmidbauer, E. \& Petersen, N., 2002. Magnetic properties and Mossbauer spectra of urban atmospheric particulate matter: a case study from Munich, Germany. Geophysical Journal International 150, 558-570.

Naumova, Y. Y., Eisenreich, S. J., Turpin, B. J., Weisel, C. P., Morandi, M. T., Colome, S. D., Totten, L. A., Stock, T. H., Winer, A. M., Alimokhtari, S., Kwon, J., Shendell, D., Jones, J., Maberti, S., Wall, S. J. 2002. Polycyclic aromatic hydrocarbons in the indoor and outdoor air of three cities in the US. Environmental Science \& Technology, 36, 2552-2559.

Özdemir, Ö.; Banerjee, S. K., 1982. A preliminary magnetic study of soil samples from West-Central Minnesota. Earth \& Planetary Science Letters 59, 393-403.

Pope, C.A. III, Burnett, R.T.; Thun, M.J., Calle, E.E., Krewski, D., Kazuhiko I., Thurston, G.D., 2002. Lung Cancer, Cardiopulmonary Mortality, and Long-term Exposure to Fine Particulate Air Pollution. Journal of the American Medical Association 287, 1132-1141.

Sagnotti, L., Macrì, P., Egli, R., Mondino, M, 2006. Magnetic properties of atmospheric particulate matter from automatic air sampler stations in Latium (Italy): Toward a definition of magnetic fingerprints for natural and anthropogenic PM sources. Journal of Geophysical Research 111:b12, B12S22.

Schwartz, J., 1996. Air pollution and hospital admissions for respiratory disease. Epidemiology 7, 20-28.

Schwarze, P.E.; Øvrevik, J.; Låg, M.; Refsnes, M.; Nafstad, P.; Hetland, R.B.; Dybing, E., 2006. Particulate matter properties and health effects: consistency of epidemiological and toxicological studies. Human \&Experimental Toxicology, 25, 559-579.

Smith, K. E. C., 2000. Chapter II. Development and validation of a method for the trace analysis of polycyclic aromatic hydrocarbons in vegetation. In: The transfer of semivolatile organic chemicals to grassland. $\mathrm{PhD}$ thesis. Lancaster University, Lancaster.

Vriend, S. P., Van Gaans, P. F. M., Middleburg, J., De Nijs, A., 1988. The application of fuzzy c-means cluster analysis and non-linear mapping to geochemical datasets: examples from Portugal. Applied Geochemistry 3, 2-3-224.

Watkins S. J., Maher, B. A., 2003. Magnetic characterisation of present-day deep-sea sediments and sources in the North Atlantic. Earth \& Planetary Science Letters 214, 379-394.

Zielinska, B., Sagebiel, J., Arnott, W. P., Rogers, C. F., Kelly, K. E., Wagner, D. A., Lighty, J. S., Sarofim, A. F., Palmer, G., 2004. Phase and size distribution of polycyclic 
aromatic hydrocarbons in diesel and gasoline vehicle emissions. Environmental Science \& Technology 38, 2557-2567.

\section{Figure headings}

Figure 1. Arithmetic mean air concentrations for PAHs measured at the three sites (black bars represent indoor samples and grey bars outdoors). Note the change in scale of the y-axes in the right hand plots.

Figure 2. Total suspended particle (TSP) concentrations for the indoor (I) and outdoor (O) samples.

Figure 3. Saturated isothermal remanence (SIRM) of particles collected on magneticallyclean PTFE filters, normalised to the air volume (a) and particle mass (b).

Figure 4. Plot of HIRM vs. $\chi_{\mathrm{ARM}} / \mathrm{SIRM}$ for the different samples. Increasing values of $\chi \mathrm{ARM} / \mathrm{SIRM}$ indicate smaller magnetic grain size and increasing HIRM (where subsequently stable to af demagnetisation) indicates the presence of haematite. The highest HIRM values were observed for the suburban indoor air samples; possibly influenced by a cast-iron stove.

Figure 5. Relationship between SIRM and particle-bound (a) $\mathrm{B}[a] \mathrm{P}$ and (b) phenanthrene

Figure 6. Non-linear map (a 2-D projection of the multidimensional magnetic and PAH data) showing the grouping of indoor and outdoor air samples, based on $\mathrm{B}[\mathrm{a}] \mathrm{P}$, phenanthrene and SIRM (mass-normalised), $\chi_{\text {ARM }} / S I R M$, and the percentages of high-field IRM (HIRM, i.e. the remanence acquired between 300 and $1000 \mathrm{mT}$ ). The axes are unitless, representing statistical distance rather than any physical parameter.

Table 1. Summary of air samples and sites. NB Sampled air volumes in the indoor environments were always considerably less $(<30 \%)$ than the internal volume of the property (e.g., the internal volume of the CC apartment $\sim 500 \mathrm{~m}^{3}$, the largest sampled air volume 141 $\left.\mathrm{m}^{3}\right)$. 
Figure 1

\section{Lancaster Uni Campus}
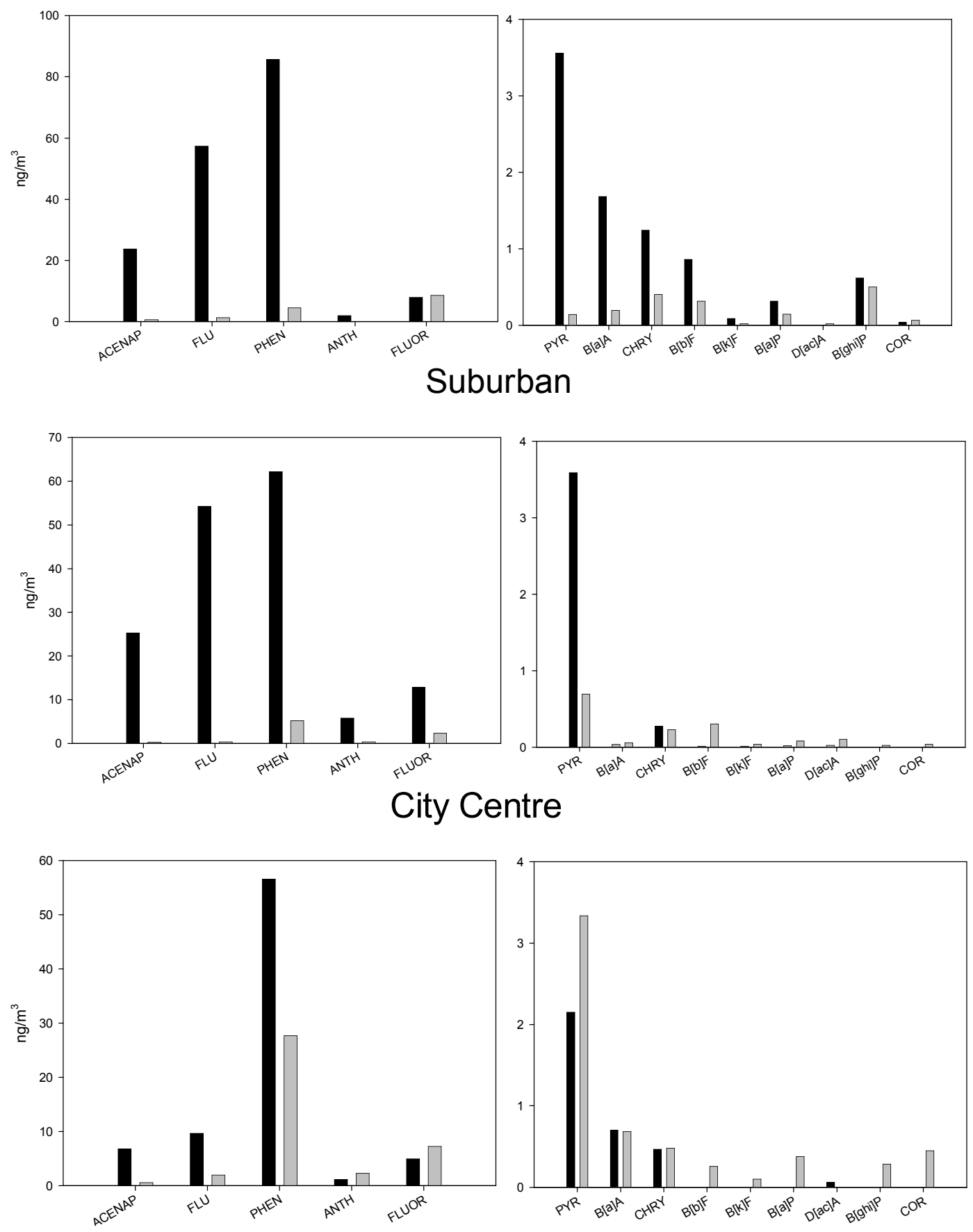
Figure 2.

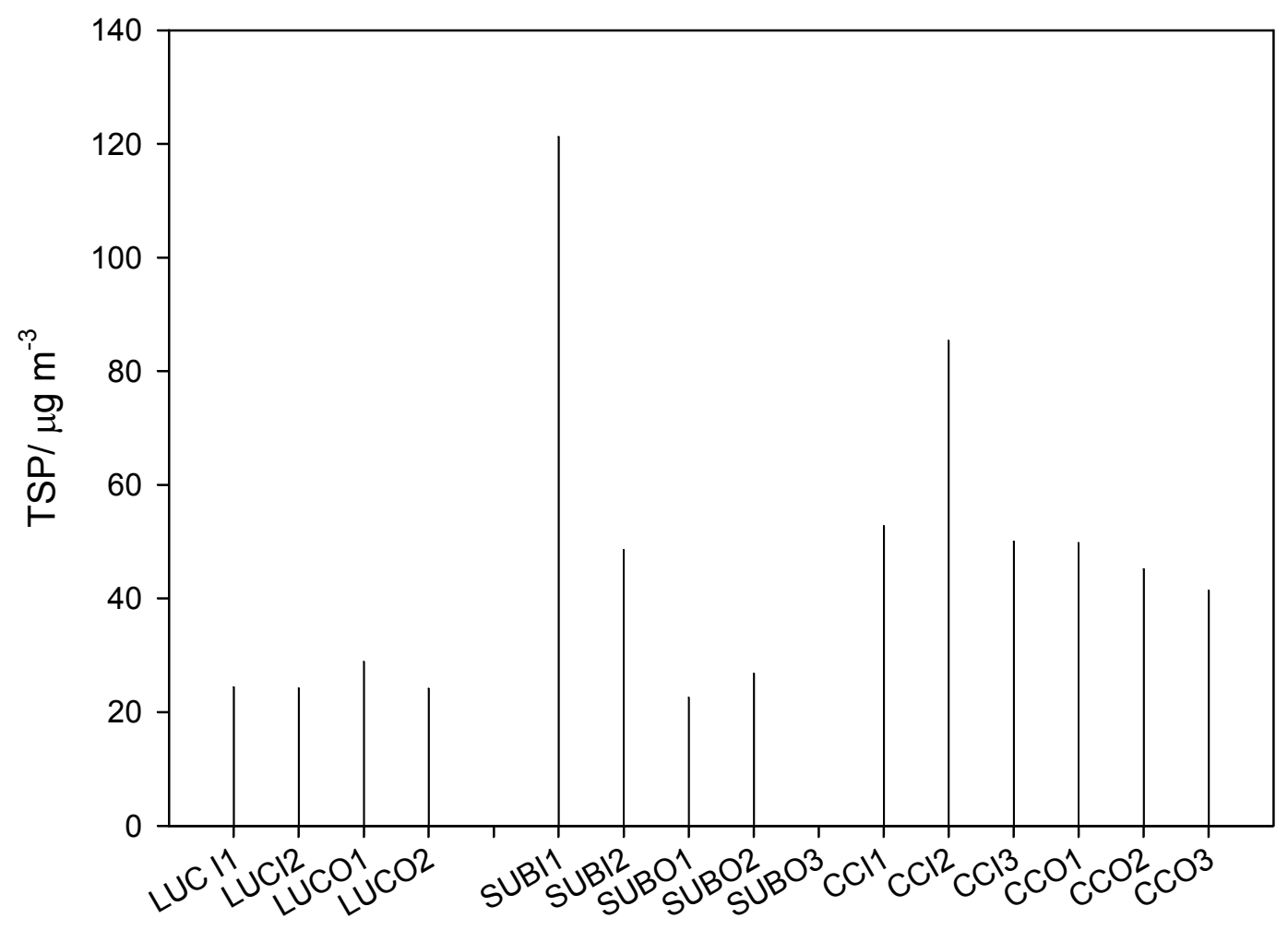


Figure 3.
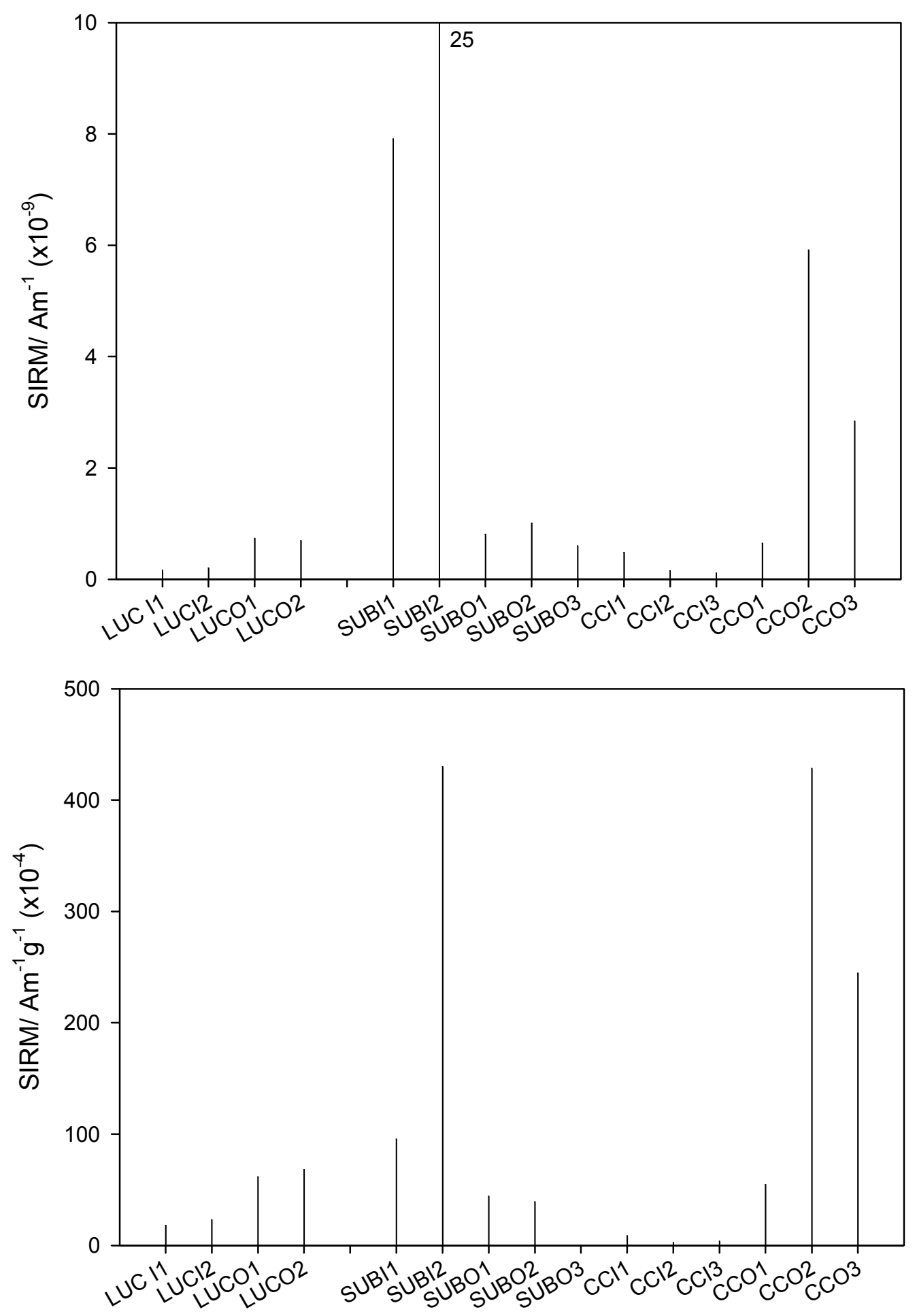
Figure 4

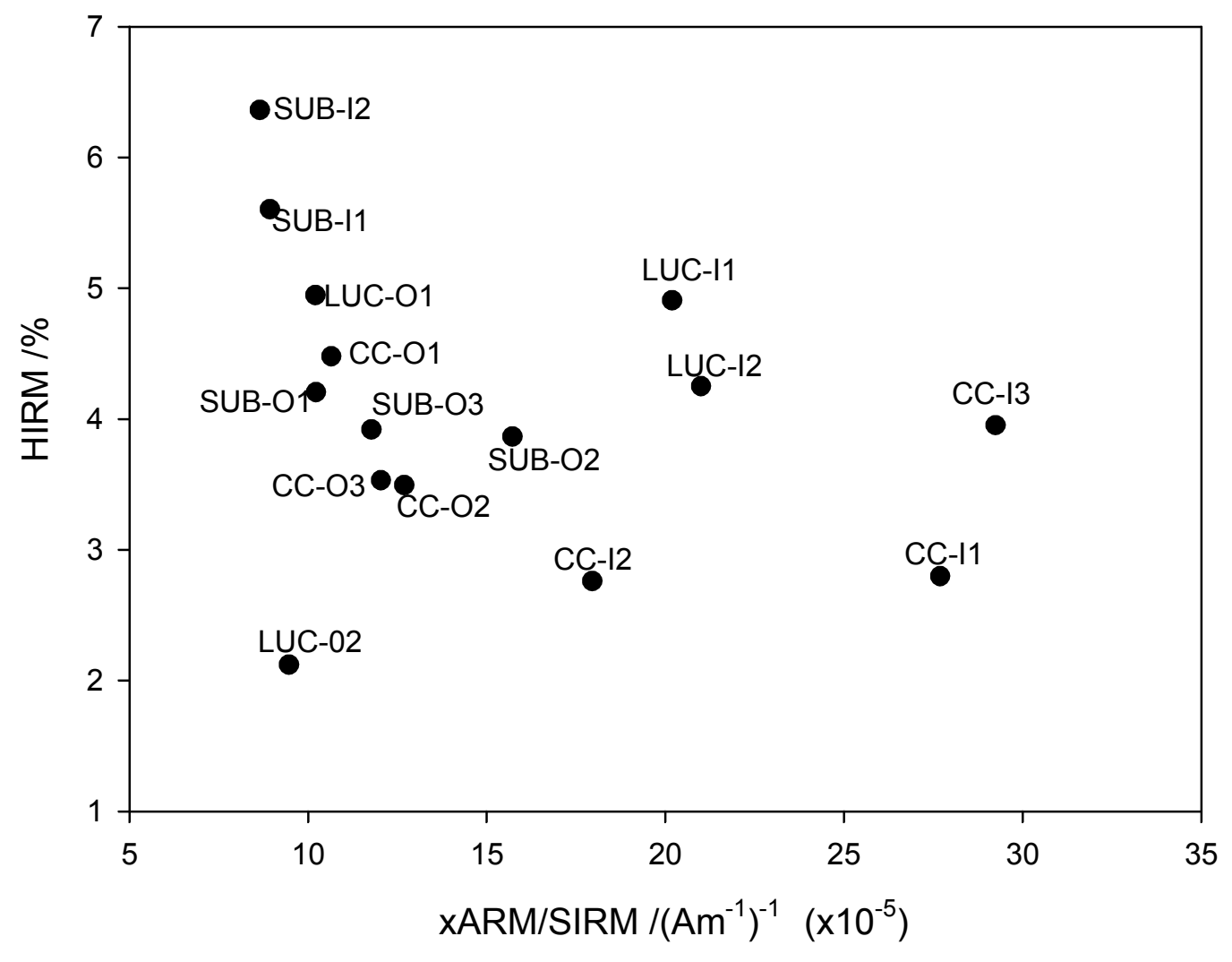


Figure5
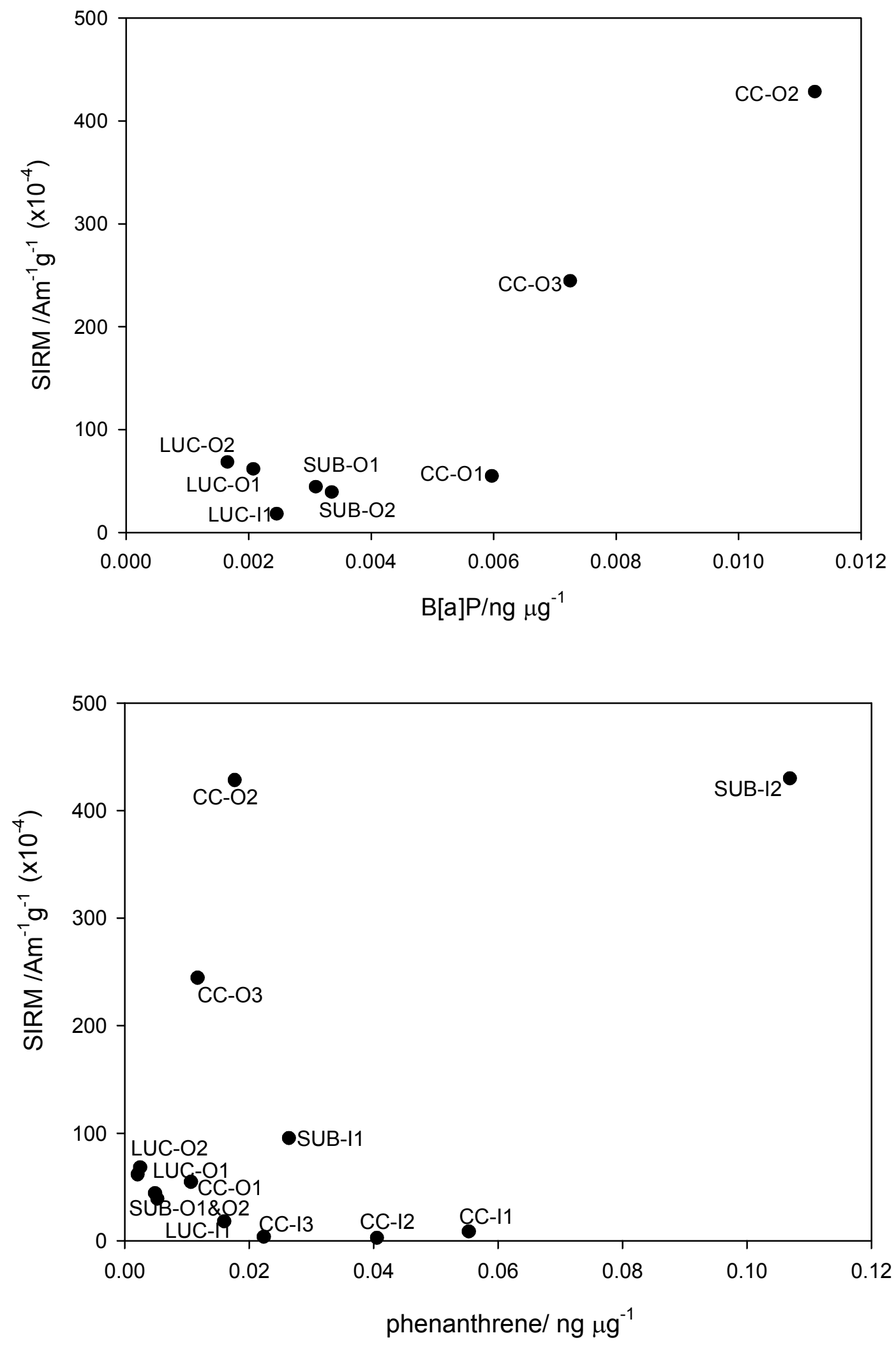
Figure 6

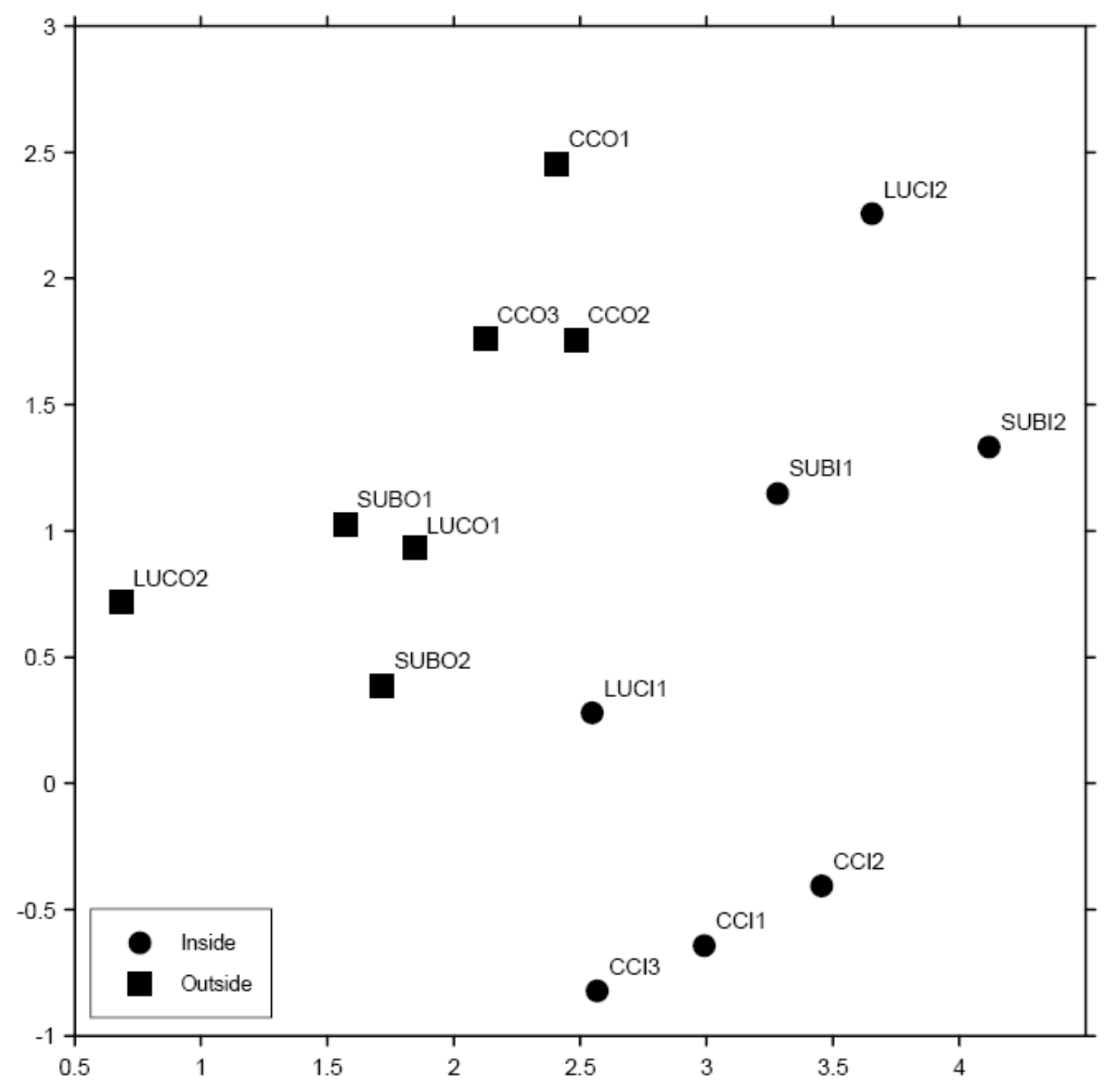


Table 1. Indoor (I) and outdoor (O) air concentrations (vapour and particle phases combined) of PAHs (ng m ${ }^{-3}$ )

\begin{tabular}{|c|c|c|c|c|c|c|c|c|c|c|c|c|c|c|c|}
\hline & \multicolumn{4}{|c|}{ Lancaster Uni Campus (LUC) } & \multicolumn{5}{|c|}{ Suburban house (SUB) } & \multicolumn{6}{|c|}{ City Centre (CC) } \\
\hline & LUCI1 & LUCI2 & LUCO1 & LUCO2 & SUBI1 & SUBI2 & SUBO1 & SUBO2 & SUBO3 & CCI1 & CCI2 & CCI3 & CCO1 & $\mathrm{CCO} 2$ & $\mathrm{CCO} 3$ \\
\hline Day of week & Sat/Sun & Mon & Mon & Tues & Fri/Sat & Mon & Mon & Tues & Wed & Wed & Thurs & Fri & Sun & Mon & Tues \\
\hline Air volume $\left(\mathrm{m}^{3}\right)$ & 113 & 142 & 128 & 212 & 123 & 63.5 & 145 & 107 & 140 & 141 & 128 & 99.8 & 263 & 272 & 350 \\
\hline acenaphthene & 1.93 & 45.7 & 0.79 & 0.71 & 18.6 & 32.0 & 0.59 & 0.08 & 0.33 & 5.87 & 7.44 & 7.00 & 1.75 & $<\mathrm{MDL}$ & $<\mathrm{MDL}$ \\
\hline fluorene & 1.88 & 113 & 1.43 & 1.38 & 40.9 & 67.6 & 0.76 & $<\mathrm{MDL}^{\mathrm{a}}$ & 0.38 & 9.20 & 11.0 & 8.76 & $<\mathrm{MDL}$ & 3.09 & 2.78 \\
\hline phenanthrene & 15.5 & 148 & 5.39 & 2.96 & 43.0 & 86.5 & 5.42 & 5.07 & 6.1 & 53.7 & 62.7 & 53.2 & 26.2 & 33.6 & 23.3 \\
\hline anthracene & 0.19 & 3.76 & 0.12 & 0.11 & 0.61 & 4.6 & 0.51 & 0.27 & 0.39 & 1.70 & 1.11 & 0.62 & 0.10 & 3.39 & 3.44 \\
\hline fluoranthene & 2.23 & 13.7 & $<\mathrm{MDL}$ & 0.86 & 1.20 & 11.1 & 1.07 & 3.69 & 2.38 & 4.38 & 8.65 & 1.92 & 8.46 & 12.7 & 0.57 \\
\hline pyrene & 1.26 & 5.86 & $<\mathrm{MDL}$ & 0.43 & 4.18 & 3.00 & 0.25 & 1.14 & 0.69 & 3.16 & 3.30 & 0.00 & 2.70 & 4.43 & 2.88 \\
\hline benzo $[a]$ anthracene & 0.23 & 3.14 & 0.07 & 0.46 & 0.07 & $<\mathrm{MDL}$ & 0.04 & 0.08 & 0.06 & 0.75 & 0.73 & 0.64 & 0.60 & 0.80 & 0.64 \\
\hline chrysene & 0.21 & 2.28 & 0.18 & 0.95 & 0.52 & 0.03 & 0.21 & 0.25 & 0.23 & 0.93 & 0.28 & 0.19 & 0.32 & 0.69 & 0.44 \\
\hline benzo $[b]$ anthracene & 0.08 & 1.64 & 0.10 & 0.81 & $<\mathrm{MDL}$ & 0.03 & 0.53 & 0.08 & 0.30 & $<\mathrm{MDL}$ & $<\mathrm{MDL}$ & $<\mathrm{MDL}$ & 0.19 & 0.40 & 0.18 \\
\hline benzo $[k]$ fluoranthene & 0.03 & 0.15 & 0.02 & 0.03 & $<\mathrm{MDL}$ & 0.02 & 0.03 & 0.05 & 0.04 & $<\mathrm{MDL}$ & $<\mathrm{MDL}$ & $<\mathrm{MDL}$ & 0.06 & 0.08 & 0.17 \\
\hline benzo $[a]$ pyrene & 0.06 & 0.57 & 0.06 & 0.04 & 0.01 & 0.04 & 0.07 & 0.09 & 0.08 & 0.01 & 0.01 & $<\mathrm{MDL}$ & 0.27 & 0.56 & 0.30 \\
\hline dibenzo $[a c]$ anthracene & $<\mathrm{MDL}$ & $<\mathrm{MDL}$ & $<\mathrm{MDL}$ & $<\mathrm{MDL}$ & $<\mathrm{MDL}$ & 0.05 & $<\mathrm{MDL}$ & 0.21 & 0.10 & $<\mathrm{MDL}$ & $<\mathrm{MDL}$ & 0.19 & $<\mathrm{MDL}$ & $<\mathrm{MDL}$ & $<\mathrm{MDL}$ \\
\hline benzo[ghi]perylene & 0.05 & 1.20 & 0.06 & 1.40 & $<\mathrm{MDL}$ & $<\mathrm{MDL}$ & 0.05 & $<\mathrm{MDL}$ & 0.02 & $<\mathrm{MDL}$ & $<\mathrm{MDL}$ & $<\mathrm{MDL}$ & 0.23 & 0.43 & 0.20 \\
\hline coronene & 0.08 & $<\mathrm{MDL}$ & 0.09 & $<\mathrm{MDL}$ & $<\mathrm{MDL}$ & $<\mathrm{MDL}$ & 0.08 & $<\mathrm{MDL}$ & 0.04 & $<\mathrm{MDL}$ & $<\mathrm{MDL}$ & $<\mathrm{MDL}$ & 0.29 & 0.65 & 0.41 \\
\hline$\Sigma \mathrm{PAH}$ & 23.8 & 338 & 8.3 & 10.1 & 109 & 205 & 9.6 & 11.0 & 11.2 & 79.7 & 95.3 & 72.6 & 41.2 & 60.8 & 35.3 \\
\hline
\end{tabular}

${ }^{\mathrm{a}} \mathrm{PAH}$ method detection limits (MDL) range between $0.01-1.5 \mathrm{ng} \mathrm{m}^{-3}$ (for $100 \mathrm{~m}^{3}$ air sample) 
